\title{
Evolution of the Teen Abortion Rate in the United States
}

\author{
Guillaume Vandenbroucke, Research Officer \\ Heting Zhu, Senior Research Associate
}

he number of teenage girls who have had an abortion has changed noticeably since the 1970s. Figure 1 shows that, during the 1970s, the teen abortion rate increased from less than 3 percent to more than 4 percent; that is, by the mid-1980s, more than 4 percent of girls 15-19 years of age had had an abortion in a given year. The abortion rate then remained stable for a decade. But at the onset of the 1990s, the abortion rate started a steady decline and was at about 1 percent by 2013 .

In this essay we analyze the declining abortion rate and point out the behavior of its components. Indeed, the abortion rate, which is the number of abortions per number of teens, depends on what we call the "abortion propensity," which is the number of abortions per number of pregnancies, and on what we call the "pregnancy rate," which is the number of pregnancies per number of teens.

Algebraically this is

$$
\underbrace{\frac{\text { Abortions }}{\text { Teens }}}_{\text {AbortionRate }}=\underbrace{\frac{\text { Abortions }}{\text { Pregnancies }}}_{\text {AbortionPropensity }} \times \underbrace{\frac{\text { Pregnancies }}{\text { Teens }}}_{\text {PregnancyRate }} .
$$

To realize what this decomposition implies, imagine that the abortion rate decreases and consider two possible, albeit extreme, scenarios:

(a) The abortion rate decreases because fewer pregnancies end with an abortion while teenage girls become pregnant at a constant rate. In this case, the decrease of the abortion rate would be driven by a lower abortion propensity, not by a lower pregnancy rate.

(b) The abortion rate decreases because teenage girls are less likely to become pregnant while each pregnancy remains equally likely to end with an abortion. In this case, it is the decline of the pregnancy rate that would drive the abortion rate.

Figure 2 shows the results of our decomposition applied to the U.S. data. We computed the annualized rate of change of the abortion rate and decomposed it between the annualized rate of change of the pregnancy rate and that of the abortion propensity. To understand the figure, focus on the first bar, which shows that the abortion rate increased 10 percent per year between 1973 and 1979. The green area

Figure 1

Teen Abortion Rate in the United States, 1973-2013

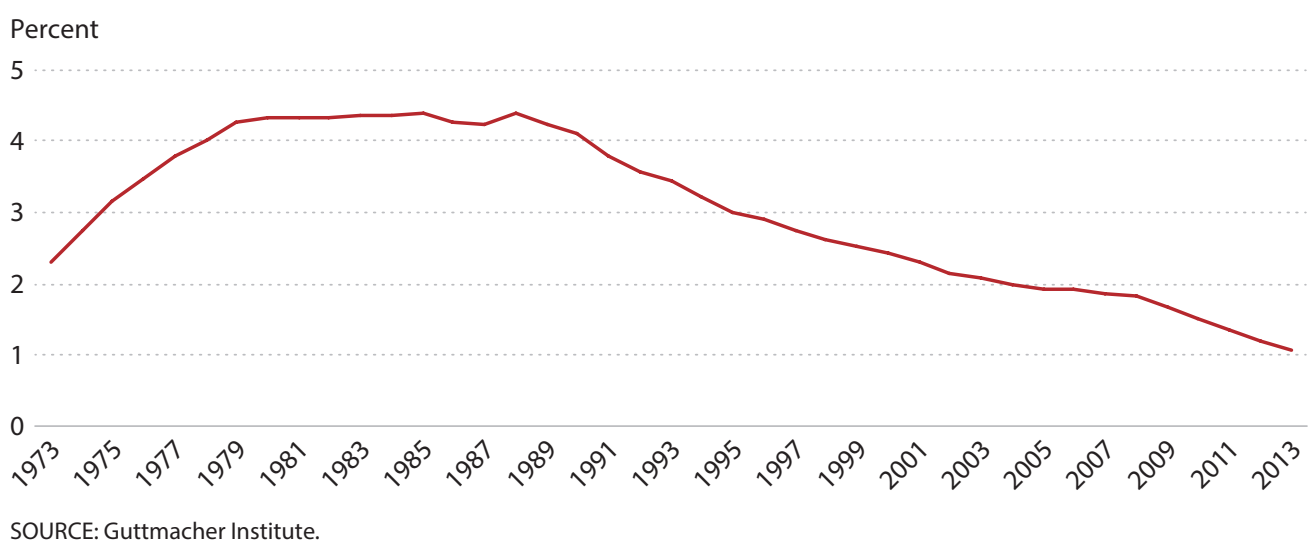

SOURCE: Guttmacher Institute. 
Figure 2

Annualized Rate of Change of the Teen Abortion Rate, by Components

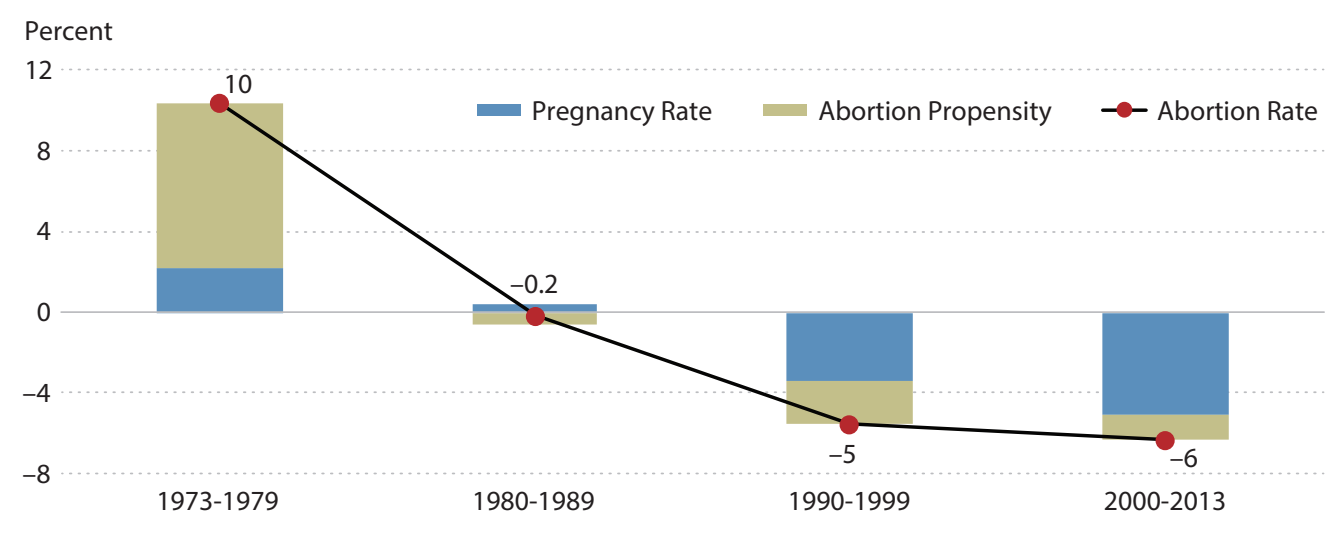

SOURCE: Guttmacher Institute and authors' calculations.

represents the contribution of the growth in abortion propensity ( 8 percent per year). The blue area represents the contribution of the growth in the pregnancy rate (2 percent per year). The sum of the change in these two components equals, by definition, the change in the abortion rate: $8+2=10$. The conclusion, therefore, is that the rising abortion rate during the 1970s resulted mostly from an increasing use of abortion to end pregnancies. ${ }^{1}$ Teenagers were also getting pregnant with increasing probability, but this played a small role.

\section{The teen abortion rate in the United States has fallen over time.}

Overall, the main message from Figure 2 is the inversion of the roles of abortion propensity and pregnancy rates. In the 1970s the (increasing) abortion rate was mostly driven by the (increasing) use of abortion; by the 1990s and 2000s the (decreasing) abortion rate was mostly driven by the (decreasing) likelihood that teenage girls would become pregnant.
Why has teenage pregnancy become less likely since the 1990s? The answer is beyond the scope of our essay. The question has been raised elsewhere, however, with some possible explanations: (i) a decline in the contraceptive failure rate and (ii) a decline in the sexual activities of teenagers. ${ }^{2}$ These are important and interesting areas for the curious reader to investigate.

\section{Notes}

1 Recall that Roe v. Wade was in 1973.

2 See Paquette and Cai (2015) and Sundaram et al. (2017).

\section{References}

Paquette, Danielle and Cai, Weiyi. "Why American Teenagers Are Having Much Less Sex." Washington Post, July 2015;

https://www.washingtonpost.com/news/wonk/wp/2015/07/22/why-americanteenagers-are-having-much-less-sex/?utm term=.6e83c7b9aaec.

Sundaram, Aparna et al. "Contraceptive Failure in the United States: Estimates from the 2006-2010 National Survey of Family Growth." Perspectives on Sexual and Reproductive Health, March 2017, 49(1), pp. 7-16; https://doi.org/10.1363/psrh.12017. 